\title{
El derecho de advenia y la construcción de los "extranjeros" en la época moderna (Estado de Saboya, siglo XVIII)
}

\section{Simona Cerutti}

Traductor. María Eugenia Albornoz Vásquez y Aude Argouse

\section{(2) OpenEdition}

\section{Journals}

Edición electrónica

URL: http://journals.openedition.org/rhj/6301

DOI: 10.4000/rhj.6301

ISSN: 0719-4153

Editor

ACTO Editores Ltda

Referencia electrónica

Simona Cerutti, «El derecho de advenia y la construcción de los "extranjeros" en la época moderna (Estado de Saboya, siglo XVIII) », Revista Historia y Justicia [En línea], 2 | 2014, Publicado el 30 abril 2014, consultado el 24 noviembre 2020. URL : http://journals.openedition.org/rhj/6301 ; DOI : https:// doi.org/10.4000/rhj.6301 


\title{
EL DERECHO DE ADVENIA Y LA CONSTRUCCIÓN DE LOS "EXTRANJEROS" EN LA ÉPOCA MODERNA (ESTADO DE SABOYA, SIGLO XVIII) $)^{1}$
}

\author{
Simona CERUTTI2
}

\section{La pertenencia local y sus derechos}

Los derechos ligados a la pertenencia local en la época moderna (tanto los derechos de la burguesía como los derechos de nacionalidad) han sido objeto, en tiempos recientes, de un debate entre investigadores que se sitúan desde posiciones profundamente diferentes y casi polarizadas. Se trata de, por una parte, investigaciones que enfrentan este tema esencialmente a partir de fuentes que emanan de instituciones - centrales o municipales - que se supone otorgaban dichos derechos; por otra parte, de trabajos que pretenden que la inserción en las redes sociales era el único auténtico criterio de atribución de tales derechos, y que, por lo tanto, el único terreno pertinente para el análisis es aquél de las relaciones. En el primer caso, las fuentes que se toman en consideración - desde los tratados jurídicos hasta las peticiones de cartas de nacionalidad y los reglamentos institucionales, etc. abrieron la vía hacia análisis a menudo importantes, que supieron mostrar hasta qué punto esa capacidad de atribución de derechos (en particular, el de nacionalidad) había sido concebido como un objetivo fundamental por los gobiernos y por las monarquías europeas, en especial para la corona francesa ${ }^{3}$.

1 El artículo "Le droit d'aubaine et la construction des 'étrangers' à l'époque moderne (Etat savoyard, XVIIIè siècle)" está publicado en Lemesle, B. \& Nassiet, M. (Eds.), Valeurs et justice. Ecarts et proximités entre société et monde judiciaire du Moyen Âge au XVIIIè siècle, Rennes, Presses Universitaires de Rennes, 2011, p. 159-176. La Revista Historia y Justicia agradece a Simona Cerutti su generosidad al haber autorizado, apoyado y acompañado personalmente la traducción de su artículo. También agradecemos la inmediata autorización de traducción y publicación otorgada por Pierre Corbel, Director de Presses Universitaires de Rennes.

2 Doctora en Historia (EHESS de Paris). Directora de Estudios, EHESS de Paris, Francia. Investigadora en LaDéHiS (Laboratoire de Démographie et Histoire Sociale), Centre de Recherche Historique (CRH). Profesora en la EHESS de Paris, Francia.

${ }^{3}$ Pienso especialmente en el libro de P. Sahlins, Unnaturally French. Foreign Citizenship in The Old Régime and after, Cornelle University Press, Ithaca and London, 2004. 
A esta metodología, que se puede calificar de "institucional", se opusieron objeciones de peso; la principal de ellas surge de una constatación aparentemente banal, compartida por investigadores de áreas geográficas variadas: el número relativamente restringido de cartas de naturaleza (o bien de burguesía) respecto de la cantidad considerablemente más importante de personas que, al mismo tiempo y en fuentes variadas, se declaran "burgués" de tal ciudad, o "natural" de tal Estado, y son reconocidas como tales ${ }^{4}$. Esa distancia plantea problemas difícilmente abordables y abre interrogaciones acerca del estatus de las fuentes en sí mismas: las "cartas", ¿son resultado de un procedimiento ordinario de petición y de atribución de derechos? ¿ $\mathrm{No}$ serían más bien el indicador de una situación rara, relativamente excepcional, que señala un conflicto social que la autoridad pública debió arbitrar? Este argumento ha sido planteado recientemente por Tamar Herzog en un libro importante ${ }^{5}$. Trabajando España y las colonias americanas, Herzog demuestra que el estatus de vecindad no estaba ligado al cumplimiento de ciertas condiciones legales, o bien, a la atribución, de parte de las autoridades, de privilegios formalmente otorgados. Vecino es aquél que actúa en tanto miembro de una comunidad, que (a través de sus actos, el pago de impuestos, la participación en las milicias, la utilización de recursos comunitarios, etc.) manifiesta la voluntad de ser parte de la vida comunitaria. Además, la investigación muestra hasta qué punto la noción de naturaleza, que refiere a la pertenencia al Reino, se construye desde una relación de continuidad con la escala comunitaria. Es a través de su relación con la comunidad local que la gente ocupaba un lugar en el reino.

Mi experiencia en la investigación me lleva a compartir ampliamente tanto las elecciones metodológicas que se siguieron en esta última obra, como una buena parte de sus resultados 6 . Trabajando sobre el Estado de Saboya durante la época moderna, me confronté al mismo ideal contractualista y voluntarista de la "cittadinanza" (término que designa la pertenencia, al mismo tiempo, a la ciudad y al Estado). "Cittadino" era aquél que manifestaba la intención y la capacidad de llenar un contrato social, de "construir junto con otros" la ciudad, o bien el País. La pertenencia local se presentaba entonces como un proceso, públicamente reconocido, e inscripción en un tejido social, y no como un estatus otorgado por las autoridades centrales.

Pero una vez que los derechos vinculados a la pertenencia local se han situado en el contexto de las relaciones sociales, se abre evidentemente la necesidad de precisar el significado de la palabra, sugerente, pero demasiado vaga, de “inscripción social". De

\footnotetext{
${ }^{4}$ En Francia, por ejemplo, según la investigación de P. Sahlins (citada supra), entre fines del siglo XVI y la Revolución de 1789 , cerca de cincuenta emigrados por año se dirigieron al rey, a menudo con éxito, para obtener cartas de naturalización.

${ }^{5}$ Herzog, T., Defining Nations: Inmigrants and Citizens in Early Modern Spain and Spanish America, Yale University Press, New Haven, 2003.

${ }^{6}$ Cerutti, Simona, "Justice et citoyenneté à Turin à l'époque moderne", en Garavaglia, Juan Carlos \& Schaub, Jean-Fédéric, Lois, justice, coutume. Amérique et Europe latines (XVIe-XIXe siècles), Ed. EHESS, Paris, 2005, p. 57-91; de la misma autora, Giustižia sommaria. Pratiche e ideali di giustiža in una società di Ancien Régime (Torino, XVIII secolo), Feltrinelli, Milan, 2003.
} 
calificar, en suma, ese tejido social que podía atribuir derechos formalmente reconocidos, declinándose en una multiplicidad de campos sociales. Pienso haber encontrado respuestas, que les propongo en estas páginas, trabajando a partir de dos fuentes que conciernen al "derecho de advenia"7: es decir el derecho del Rey de confiscar las propiedades de los extranjeros que han fallecido en su territorio. Esta prerrogativa es específica de la monarquía francesa y, según la mayoría de los historiadores, el derecho de advenia ha sido interpretado como el pivote de una ideología y de una política de Estado que se arroga el monopolio de la atribución e los derechos de la ciudadanía; ese derecho de advenia es, precisamente, el responsable de la producción de esas cartas de naturalización, las únicas que permitían escapar de las confiscaciones de bienes.

Sin embargo, trabajando en las fuentes producidas por ese derecho, en el marco del Estado de Saboya, específicamente sobre los procedimientos de confiscación, las cosas aparecieron bien distintas de esa imagen. Las intervenciones de los funcionarios reales en el caso de las sucesiones de "extranjeros", aunque violentas y precipitadas, transparentan los contornos de una demanda social sobre las garantías de control y de puesta en orden de una transmisión patrimonial incierta. A través de esa fuente aparecen trazos de una cultura de la propiedad y de su transmisión, que nos es todavía ampliamente desconocida. Las fuentes relativas al derecho de advenia están repletas hasta desbordar de esta cultura "propietaria", y también de sus estrechas relaciones con la atribución de la ciudadanía y de la nacionalidad. Es exactamente este vínculo entre línea de sucesión y derecho de ciudadanía lo que hace improbable, a mi parecer, la imagen de una superpotencia por parte del Rey en esta materia, y plantea que nos interroguemos sobre lo que ha sido pedido a la institución, y sobre el sentido de su actuación. Esta lectura, lo veremos, invita a situar los temas de la ciudadanía y de la integración en contextos diferentes respecto de aquéllos que han sido privilegiados por las ciencias sociales a partir del siglo XIX, a saber las relaciones entre particulares y Estados centrales. Nos encontraremos con individuos cuya "extranjeridad" se mide más sobre las líneas de sucesión que sobre la pertenencia a un territorio; con individuos que son extranjeros a ciertos grupos, no a las patrias.

\footnotetext{
${ }^{7}$ La expresión francesa "droit d'aubaine", que en italiano piamontés se denomina "diritto de ubena", tiene diversas traducciones. Hemos escogido aquí "derecho de advenia", palabra que tiene la misma raíz que advenedizo, porque pensamos que facilita su comprensión histórica (hemos descartado las otras denominaciones, "derecho de aubana" o "derecho de aubena"). En España, este derecho se habría usado como efecto de reciprocidad frente a otros reinos que lo cobraban sobre los bienes de los súbditos españoles que fallecían en tierras extranjeras. España solía darle la forma de un tributo sobre los bienes de los extranjeros sin heredero que fallecían en el reino. Las normas y reglamentaciones que lo conciernen, dictadas a lo largo de los siglos, buscan más bien eximir a los extranjeros de esta restricción que imponerla. Ver Patricio de la Escosura, Diccionario Universal del Derecho Español, Madrid, 1853, p. 90-99, entrada "Derecho de Advenia". Agradecemos a Alejandro Agüero, consejero de la Revista Historia y Justicia, esta útil referencia.
} 


\section{El derecho de advenia en el Estado de Saboya}

Postulando una incapacidad de los extranjeros a disponer de sus propios bienes, la aplicación del derecho de advenia podía evidentemente ser un arma de doble filo para Estados con frecuencia carentes de población. Así, al igual que en Francia, en el Estado de Saboya la ley fue promulgada en diferentes momentos, y en muchas ocasiones fue derogada con el fin de solicitar nuevos flujos migratorios en el territorio ${ }^{8}$. Este movimiento irregular debe ponerse primero en relación con la contingencia política que atravesaba el Estado. Entre el 28 de junio y el 25 de septiembre de 1618, por ejemplo, su aplicación respondió a una voluntad de represalias respecto de súbditos lombardos del rey de España, mientras que en las décadas de 1690, 1720, 1740, se enfocaron en los franceses y en los "reformados", en particular los Valdenses. La contingencia económica también jugaba un rol importante en las vicisitudes del derecho de advenia (como, de hecho, sucedía en el caso francés). Luego de la peste de 1630, por ejemplo, que había diezmado la población y destruido la vida económica del Estado, la suspensión del derecho de advenia debía servir para estimular los flujos migratorios asegurando a los nuevos llegados los mismos derechos de sucesión de que disfrutaban los "locales"; sucedió lo mismo, a inicios del siglo XVIII, cuando el nuevo éxito de la industria de la seda requirió una demanda creciente de obreros y de artesanos?.

Sin embargo, se trata de raros momentos en que la suspensión del derecho de advenia fue una medida general. Con frecuencia, al igual que en Francia, el soberano del pequeño Estado de Saboya prefería disponer de esta materia de manera más personalizada, acogiendo las peticiones de cartas de naturaleza que le estaban destinadas y que habían sido redactadas por particulares; a veces, ofreciéndoles bajo forma de "don gracioso", con frecuencia obteniendo a cambio una buena suma de dinero. En el caso piemontés las fuentes están bastante dispersas ${ }^{10}$. No obstante, como acabo de

\footnotetext{
${ }^{8}$ Los documentos relativos al derecho de advenia en El Piemonte se hallan en el Archivio di Stato di Torino (AST), Sezione Riunite, Archivio Camerale, art. 492, Ubena; igualmente, I Archiviazione, Legge di Ubena; AST, I Sezione, Materie economiche, Ubena. Sus características se construyen sobre la base del derecho francés, con el cuál los juristas piemonteses comparten las auctoritas. Para algunos datos locales ver Mansord, A., Le droit d'aubaine en Savoie, Chambéry, 1824; Capuano, L., "L'Albinaggio", Enciclopedia Giuridica Italiana, Torino, 1884; Gianzana, S., Lo straniero nel diritto civile, Torino, 1884; Scopi, M. C., Ricerche storico-giuridice sul diritto d'ubena negli Stati sabaudi con particolare riguardo alla legislazione militare, Tesis de Licenciatura, Universidad de Turin, 1997-1998.

${ }_{9}^{9}$ En 1701, el Reglamento del Consulado de Comercio (el tribunal competente para las causas comerciales), invitaba a todo extranjero que quisiera establecer un negocio y manufacturas en Turin o en cualquier villa del Estado, a visitarlo sin vacilar, con la certeza de poder gozar de todos los privilegios y especialmente, de la exención del xxx: "Editto di S.A. pel nuovo regolamento del Consolato di Torino, e modo di procedere avanti ad esso, con privilegi a favore dei forestieri di introdurre nello stato nuove manifatture e provvedimenti per impedire la migrazione all'estero de lavoranti in seta", en Duboin, F. A., Raccolta per ordine di materia di leggi, provvidenze, editti, manifesti, ecc., pubblicati dal principio del anno 1681 sino alli 8 dicembre 1789, Torino, Arnaldi, 1818-1868, t. III, p. 808 y sgtes.

10 No pude encontrar series relativas a las cartas de naturalización. Sin embargo, ellas son citadas con frecuencia en los "Patenti Piemonte" y "Patenti Controllo Finanze" (AST, Sez. Riunite; fuente organizada por orden alfabético, a partir del nombre del pleiteante). Informaciones complementarias se encuentran en una fuente que reúne los juramentos de fidelidad que han prestado los extranjeros residentes en El Piemonte:
} 
decirlo, esas cartas son extremadamente raras respecto de la masa de personas que reivindicaban dichos derechos. De hecho, los postulantes declaraban, con frecuencia, querer obtenerlos "per cautella" (por cautela y precaución) más que por necesidad"1. De todas maneras, su presencia estaba lejos de ser decisiva. Será considerada como menos importante que un testamento que designa herederos, por ejemplo, en el caso en que se trata de suspender una confiscación ${ }^{12}$. Vamos a considerar detalladamente cada uno de esos puntos.

Los expedientes para obtener las cartas de naturaleza son documentos ricos y útiles, pero otras fuentes pueden ayudarnos a comprender mejor a qué se refería el derecho de advenia. Los cientos de procesos de petición de derecho de advenia por parte de "extranjeros nacidos fuera del Estado de $\mathrm{Su}$ Majestad, o bien fallecidos sin descendencia", tal como lo formulaba el título de uno de los numerosos volúmenes ${ }^{13}$, son documentos llenos de información que desestabiliza. Empezando por el acercamiento, para nada evidente, que acabo de evocar: "extranjeros", o bien fallecidos sin descendencia: ¿qué relación establecen los contemporáneos entre esos términos? Allí está, a mi juicio, una de las claves para entender no sólo la institución del derecho de advenia sino también las concepciones de lo extranjero y de la nacionalidad en la época moderna.

\section{Los procedimientos de la confiscación de bienes}

El rasgo más sobresaliente de los procedimientos de confiscación es su afiebrada precipitación. Una vez solicitados por la denuncia de los propietarios de los inmuebles, por los que acogen a los extranjeros, como lo prescribe la ley, o incluso por muchos particulares que esperan, a cambio, un cuarto de los bienes de los de cujus, los funcionarios del rey que irrumpen en la escena del fallecimiento y que producen documentos de un extraordinario valor etnográfico. A inicios del siglo XVIII todo se registra con una gran riqueza de detalles: desde la posición y aspecto del cadáver, hasta la presencia de los médicos, de sacerdotes, de mujeres o incluso de los sirvientes que habrían asistido al que muere, y sobre todo, de vecinos y amigos, de parientes o de sus cófrades, de todos ellos se anotan cualquier movimiento y cualquier palabra dicha. En 1733, luego de haber recibido información en la Oficina del Procurador General de Su Majestad sobre el fallecimiento de los cónyuges Rochelli, "uno romano y la otra genovesa", el delegado del Fisco Real, acompañado de un guardia y de un notario que

"Testimoniali di giuramento di fedeltà prestato da esteri venuti ad abitare in questi stati (1637-1698)", AST, Sez. Riunite, Camerale Piemonte, art. 835. (Se trata de un centenar de documentos).

11 AST, Sez. Riunite, Camerale Piemonte, Ubena, art. 492, m. D/F-1, Margherita Mirapel, 1715.

${ }^{12}$ Ejemplar, en este sentido, es la causa que concierne a Francesco Cousin de Lyon, in ibid., m. C, 1728.

${ }^{13} \mathrm{El}$ fondo (citado supra), está compuesto por cerca de sesenta legajos, organizados por orden alfabético, que contienen muchos fascículos y que cubren el período de mediados del siglo XVI hasta fines del siglo XVIII. He explorado la totalidad de los expedientes; he transcrito cerca de 300 (de los cuáles, 150 datan del periodo 1680-1730). La dimensión de los expedientes es variable: desde algunas decenas hasta muchos cientos de páginas. 
cumplió el rol de secretario, se apersonó en la casa, en la parroquia de San Felipe. En una pequeña habitación situada en el segundo piso, encuentran el cadáver de una mujer en una caja, "rodeado de una niña de cierta edad, que dice llamarse Margherita Dagnassa, que vive en las habitaciones vecinas". Ella les entrega detalles sobre la identidad, las condiciones de muerte de los cónyuges (la del marido había sido constatada? apenas algunos días antes), y sobre todo, acerca de la existencia de eventuales herederos ${ }^{14}$. El hecho es que Margherita ha oído decir que la difunta tenía un hijo de su primer matrimonio, que sería soldado en la armada piemontesa, pero no puede decir más. Sin embargo, ejerce funciones de ejecutor testamentario, atestiguando la voluntad de la difunta de regalar un cuadro que representa a Jesús y María a una pobre mujer que les asistió en su enfermedad, lo que es aceptado por el Fisco. En seguida se procede al inventario de los bienes de los cónyuges (algunos muebles de modesto valor), y a la convocatoria y satisfacción de los acreedores (el médico, un panadero, dos vecinos). Es sólo al final de este largo procedimiento que el Fisco se apodera de una modesta suma de dinero que, en este caso, ni siquiera alcanza para cubrir el costo del procedimiento ${ }^{15}$.

En el caso de Pietro Tassinari alias El Romano, saltimbanqui, "nativo de la ciudad de Roma, súbdito sujeto al derecho de advenia , sobre todo ["massime"] a causa de la ausencia de infante cerca suyo" las cosas son más complicadas y también más interesantes ${ }^{16}$. Una mujer y dos hombres rodean el cadáver, a quiénes se les pide, como es la costumbre, "presentar e indicar los objetos, el dinero, los créditos y las deuda y cualquier otra cosa" que hubiera podido pertenecer al dicho Pietro Tassinari. Esta vez los bienes son muy numerosos: un gran número de muebles (armarios, buffets, sillas, camas, etc.), ropas, disfraces e instrumentos útiles a su oficio de saltimbanqui, "charlatán y sacador de muelas"17. Luego de un inventario detallado, que demora toda la jornada, cada pieza es cuidadosamente cerrada con los emblemas del Rey; las cerraduras de los muebles se taponean con papel blanco; las escrituras y libros de cuentas se reúnen y protegen de posibles intrusiones con sellos de cera. De esta manera los "bienes son reducidos bajo la mano del Rey". Pero, nuevamente, esa "reducción" es sólo la fase inicial de una vicisitud cuya duración depende esencialmente de factores de dos órdenes: la presencia eventual de individuos "reivindicando sus derechos" (y la transparencia o la opacidad de sus reivindicaciones); la presencia y la cantidad eventual de acreedores que reclamarán la restitución de lo que se les adeuda (y de la solidez de las pruebas que podrán proporcionar). Con este fin el procedimiento se hace público, acompañándose de "citaciones públicas" para solicitar a "todos los pretendientes que sean o quieran ser herederos del dicho Tassinari". El Secretario del Fisco se presenta, así, como el "curador de los inciertos y de los ausentes"18. En el procedimiento de

\footnotetext{
14 AST, Camerale Piemonte, art. 492, Ubena, m. R-S-T/3, 1733.

15 Una evaluación detallada de los costos del procedimiento en ibid., m. O, 1725 (proceso Sebastiano Olier).

16 Ibid., m. R-S-T/3, 1735.

17 Ibid., 10 de diciembre, "Atto di prova di notorio".

18 Ibid., Testimoniali..., 13 de julio de 1735; yo subrayo.
} 
Tassinari, esta publicidad solicita inmediatamente numerosas comparecencias: del abogado Marandono, primero, quien se presenta como procurador del médico Pietro Paolo Calvi, del Señor Giovanni Batista Giordano, de la viuda Vittoria Bordoni y de seis otros individuos, todos acreedores del saltimbanqui debido a "numerosas visitas y consultas" desde que su salud se había debilitado, por "medicamentos y cuidados prestados", por sumas de dinero pedidas a lo largo de toda su vida. Algunos reivindican la propiedad de ciertos muebles encontrados en la casa de Tassinari. Paralelamente, otros se convierten en los portavoces de los derechos de una supuesta hija natural del difunto, Giovanna, de 7 años de edad, a quién la Cámara de Cuentas ha asignado como curador el abogado de pobres ${ }^{19}$. Los delegados de la Cámara de Cuentas evalúan las pretensiones de cada uno, filtran sus argumentos pronunciándose acerca de la validez o verosimilitud, analizan los escritos de prueba que presentan los acreedores y escuchan los testigos eventuales. Finalmente, luego de decenas de interrogatorios, de comparecencias, de debates acerca de la validez de las pruebas producidas, los delegados de la Cámara de Cuentas reconocen la existencia y sobre todo la legitimidad en la sucesión de dos hermanos, que residen en el poblado de Giuliano, muy cerca de Roma. Estos últimos habían entregado un poder de representación a un notario para que representase sus intereses. Como prueba de sus identidades, habían podido producir las actas de bautizo de la parroquia de Giuliano. Pero, más que estos documentos, fueron decisivas, en el juicio, las palabras de dos testigos, quiénes dijeron haber visto muchas veces, a lo largo de los años, a los dos hombres compartir la casa de los Tassinari y ser tratados "como verdaderos hijos" por los parientes ancianos ${ }^{20}$.

El Fisco renuncia entonces a sus pretensiones, independientemente de que Tassinari era un extranjero sin sucesión legítima nativa del Estado, y a pesar del edicto relativo al derecho de advenia, y al mismo tiempo, reconoce la legitimidad de una sucesión que define como pasando "de romano a romano".

Por lo demás, como acabamos de ver, no se pone término al secuestro de bienes. Ello es así porque, aunque se miren de cerca y minuciosamente las expectativas de los más próximos al difunto, la acción de los Agentes del Fisco nunca se identificó con la apropiación de los bienes de un extranjero fallecido. Se trataba más bien de una medida

\footnotetext{
${ }^{19} \mathrm{El}$ abogado de pobres es una figura relativamente original en el marco europeo del primer siglo XVIII. Acerca de su creación en El Piemonte, lo que suscita el interés de K. Marx y F. Engels, ver Dogliani, M., "L'avvocatura dei poveri: dal privilegio dal foro al gratuito patrocinio", in Passato e Presente, 19, enero 1988, p. 275-289.

${ }^{20}$ Son las palabras que aparecen en los últimos párrafos del proceso, en el momento en que El Fisco retira sus pretensiones: ibid.. En efecto, esta distribución de la familiaridad en el tiempo largo parece un elemento esencial; otros testimonios no son considerados pertinentes porque han sido entregados por personas extranjeras, que habían conocido sólo esporádicamente a los esposos Tassinari ("persone forestiere e che la conoscenza contratta da essi con detti giugali Tassinari fu veramente accidentale, che non ba potuto dar aggio di tempo nell'internarsi nella figliazione suddetta"); porque la co-residencia no era por si misma suficiente para probar la existencia de una relación de parentela ("la sola co-babitazione ... non è bastante a stabilire la prova della figliazione"). Se necesitan acciones y esos intercambios que, de costumbre, existen entre parientes e hijos ("solite farsi tragenitori e figli"). Ibid., I, 10 de diciembre.
} 
de prudencia, que buscaba suspender el estatus de los bienes con el fin de verificar la presencia de herencias legítimas y defender los intereses de los acreedores. Eso es lo que se recuerda con frecuencia en los procesos; el Fisco describe su propia función como la de "curador de los inciertos" y de los ausentes que pretenden ser herederos legítimos o bien tener interés en los derechos sobre la herencia ${ }^{21 " . ~ M a ́ s ~ q u e ~ m a e s t r o ~ y ~}$ señor de las propiedades de los extranjeros, como podría pretender serlo según el derecho de advenia, el Fisco actúa como curador de la herencia en el marco de una sucesión incierta. El Fisco podría proceder a una apropiación sólo en el caso en que la herencia se transforme y pase de incierta a "vacante", es decir en el caso en que ningún heredero legítimo sea reconocido. Por lo demás, incluso en los casos relativamente raros, la confiscación se presentará no como la reivindicación de un derecho legalmente reconocido, sino más bien como la consideración de una responsabilidad esencial al buen orden de la vida social: la necesidad de proveer un heredero.

En efecto, es necesario que toda herencia tenga un heredero, por una razón a la vez simple y esencial: la existencia de acreedores a los que se debe satisfacer. El intercambio y el mercado sólo pueden existir con esa condición; y es la necesidad de materializar esta necesidad lo que suscita una demanda social legitimadora de la intervención de la institución central.

La afirmación de los teóricos del derecho de advenia, según la cual el extranjero sería aquél "que no tiene familia" 22 no debía referirse tanto (o no solamente) a una necesidad de protección paternal que el rey hubiera podido, por defecto, satisfacer el extranjero necesita con frecuencia un hijo, o para decirlo mejor, un heredero legítimo (vamos a ver que los dos términos pueden no coincidir). El Rey viene a prestarles ayuda como si él fuera un hijo (es decir, como heredero). Las ventajas materiales que acompañan la confiscación eventual de los bienes de los extranjeros son envidiadas, evidentemente; pero ellas pueden reclamarse sólo después de haber agotado la primera fase de las confiscaciones: la satisfacción de los acreedores.

Alrededor del 60\% de los aproximadamente 300 procesos que analicé terminan con la "levata della mano regia" (es decir, la renuncia del Fisco) y el reconocimiento de un heredero legítimo. Las acciones violentas de los funcionarios no fueron entonces dictadas por la avidez. En la mayoría de los casos, herederos reales o pretendidos empujaron al Fisco a retirar sus propias pretensiones. En la totalidad de los casos, de hecho, este último actuó como garante "de las razones de los acreedores", y no abandonó el proceso sino sólo después de haber actuado en su defensa. En el largo proceso relativo a los bienes del Señor Claudio Fournier, fundidor de metales de Su Majestad, de nación francesa, fallecido en 1709, el Fisco impuso a su esposa retirar su propia dote del conjunto del patrimonio y proceder por fin a la satisfacción de los

\footnotetext{
21 Esta fórmula figura en el título del primer expediente del proceso Tassinari, ibid.

22 Es lo que afirman, entre otros, Antoine de Loysel y Pierre Jacques Brillon, citados por Sahlins, P., Unnaturally French, Op. Cit., p. 37.
} 
numerosos acreedores ${ }^{23}$. Igualmente, para el caso de los bienes de Giovanni Arnò, conocido bajo el alias de La Touche, peluquero originario de París: su esposa no sólo "había tomado posesión de todas las cosas, muebles, platería y todo objeto relevante de su propia herencia, pero había continuado con su negocio de las pelucas [...]”, y ello, ignorando las prerrogativas del Patrimonio Real. Se procede entonces a confeccionar el inventario de toda propiedad, pero no se deduce ninguna confiscación, porque el Fisco se conforma con la promesa jurada de la viuda de quiere "conservar y guardar esos bienes para poder remitirlos a quiénes tiene derecho sobre ellos, siguiendo así la decisión de la justicia". En suma, la viuda, declara estar dispuesta a satisfacer a los numerosos acreedores de Arnò, cuyos intereses eran representados por Agostino Bello, primer cirujano de Madame Royale. Es la solución deseada por el Fisco, que abandona así una causa en la que su rol ha sido el de garante y protector de los intereses de los acreedores ${ }^{24}$. Los casos similares son muy frecuentes ${ }^{25}$.

El Fisco cumple la función de garante de "los que tienen derecho" sobre la herencia; esa función legitima su acción cuando suscita una petición que los particulares le dirigen. Los funcionarios están lejos de actuar como voraces acaparadores. Su actuación, que a veces puede efectivamente desembocar en la confiscación de bienes de los de cujus, se desarrolla en un marco en el que debe dominar el acuerdo entre partes, más que la afirmación de los derechos provenientes de la ley ${ }^{26}$.

Los procedimientos inspirados del derecho de advenia nacen de la petición de "puesta en orden" de una sucesión dudosa y quizá inexistente; "el Patrimonial de Su Majestad es designado para la sucesión a falta de verdadera sucesión”, se anota en un procedimiento de 169727 . Nacen igualmente de la petición de protección contra los atentados que esa falta de certeza puede provocar en los miembros particulares de la comunidad, los acreedores. No se trata aquí de ninguna intención punitiva respecto de los extranjeros. La fuente de legitimación de la intervención del Estado no es, repito, ni la represión ni el castigo del extranjero (¿cómo podría ser eso posible?): es más bien una protección hacia súbditos jurídicamente débiles, esos "miserables", entre los cuales figuran los extranjeros ${ }^{28}$.

\footnotetext{
23 AST, Camerale Piemonte, art. 492, Iena, m. D/F2, Claudio Fournier, 1709.

24 Ibid..: m. A. B/2, Giovanni Arnò, La Touche, 1726.

25 Ver en particular ibid., Pietro Archier, 1693; ibid., m. R.S.T./3, Antonio Thomé, 1730; ibid.., m. P3, Pietro Paschè, 1746.

26 Respecto de esta vocación hacia el consenso de la acción judicial en el periodo moderno, son fundamentales las observaciones de Hespanha, M. A., por ejemplo, en "Pré-compréhension et savoir historique", Ratthistorika Studier, XIX, 1993, p. 49-67.

27 Ibid., m. A-B1, 1697, Pietro Broglio.

${ }^{28}$ Acerca del derecho de los miserables, ver Cerutti, S., “Justice et citoyenneté à Turin...”, Op. Cit.
} 


\section{La vulnerabilidad de los bienes}

Los procedimientos inspirados por la ley eran precipitados, casi afiebrados. Lo hemos visto, los funcionarios están listos a pagar holgadamente a los informantes que les permitan intervenir pronto sobre la escena del fallecimiento, de encontrarse frente al cadáver, de registrar in situ presencias humanas o materiales. Si no podemos acceder a la explicación de la avidez (y ya hemos visto que no podemos proporcionarla), ¿cómo interpretar el apuro afiebrado que caracterizaba sus intervenciones?

Existe un rasgo de la cultura de las sociedades modernas que abunda en la mayoría de los archivos de familias y en las fuentes surgidas de los procesos civiles: la falta de certeza respecto de la propiedad. Se trata de un rasgo bien conocido, con frecuencia subrayado por investigadores consagrados a la economía de Antiguo Régimen ${ }^{29}$, del cual sin embargo, a mi juicio, no hemos medido de manera suficiente el peso que tiene en muchos campos de la vida social. ¿A quién pertenecen esas mercaderías, esos bienes, esos muebles, esos objetos? ¿Cómo puedo yo comprar un bien si no tengo certeza respecto de su proveniencia? ¿Si yo puedo temer que mi compra sea invalidada por los pretensiones de otros propietarios? ¿Cómo lo puedo transmitir, bajo la amenaza de esa falta de certeza? Las fuentes relativas al derecho de advenia hablan exactamente de esa obsesión, y es a través del prisma de la propiedad que se enfrenta el tema de la nacionalidad.

Muchos elementos contribuyen a crear falta de certezas alrededor de la propiedad. Quisiera analizar algunos, comenzando por aquél al que se vinculan algunos rasgos distintivos de la fuente, el apuro de los funcionarios. Los hemos seguido, alocados, desplazando emblemas reales, o sellando a toda velocidad cofres y muebles para protegerlos de eventuales tomas de posesión. ¿Por qué? ¿De dónde viene esa vulnerabilidad de los bienes?

La cultura "propietaria" de la que encontramos huellas en estos procedimientos se nutre de elementos diversos, de los cuáles muchos, evidentemente, tienen su origen en el derecho romano; otros son más bien una corrección de él. El estatus del heredero es un buen ejemplo del sincretismo del derecho común. La sucesión no está ligada al acto de la aditio, es decir de la aceptación formal y voluntaria del destinatario. En la práctica sucesoria vigente en El Piemonte (del mismo modo que en Francia), la transmisión es un proceso automático, en el que el muerto atrapa al vivo. Pero, en el caso de incertidumbre, cuando la presencia y la identidad de los herederos no se han establecido aún, los bienes (las casas, los terrenos, los objetos...) se encuentran en un estado liminal; no son propiedad de los De Cujus y todavía no han sido atribuidos a los herederos, en realidad no pertenecen a nadie. Lo que, empero, implica que pueden pertenecer a cualquiera que crea poder reivindicar derechos sobre ellos; en particular, los derechos de usufructuar, en torno a los cuáles el debate ha sido encendido, y los

\footnotetext{
${ }^{29}$ Grenier, J.-Y., L'économie d'Ancien Régime. Un monde de l'échange et de l'incertitude, Paris, Albin Michel, 1996; Ago, R., Economia barocca. Mercato e institurioni nella Roma del Seicento, Donzelli Editore, Roma, 1998.
} 
conflictos continuos. El estatus de "heredero yaciente" e bien distinto de aquél de "heredero vacante" (ambas, dos figuras jurídicas bien formalizadas por el derecho romano); el segundo señala la ausencia de herederos, mientras que el primero indica la incertidumbre, transitoria, que precede a la individualización del sucesor legítimo ${ }^{30}$. Esa incertidumbre, ese vacío, es lo que deben llenar los funcionarios. Los emblemas reales manifiestan el estado de yacencia y protegen la propiedad de los actos de posesión prematuros. El Rey reivindicará derechos a la propiedad sólo cuando la propiedad pase de ser yacente a vacante. Entre tanto, se debe actuar rápido: es necesario llegar pronto a la escena del fallecimiento para responder a las expectativas de protección de los herederos y de los acreedores ${ }^{31}$. El estatus de esas propiedades es, de hecho, bastante ambiguo. En tanto bienes "in potestate nullius" (y por lo tanto temporalmente "sine dominio", a la espera de ser atribuidos) ellos deben ser puestos al abrigo, si no es de robos, al menos de actos de posesión que podrían ser juzgados como legítimos. Pero basta considerarlos "res nullius" - una interpretación igualmente extendida, y con frecuencia planteada en los procedimientos - para que, siguiendo el principio según el cual "res hereditariae furtum non sin", pueda alguien apropiárselos legítimamente.

En todo caso el tiempo es precioso en el momento liminar que se considera cargado de peligros. Y con razón. Los procedimientos están llenos de situaciones en las cuáles las personas presentes al momento del fallecimiento reivindican, según diferentes motivos, sus derechos a la herencia.

\footnotetext{
${ }^{30}$ Entre las lecturas valiosas ver Besta, E., Le successioni nella storia del diritto italiano, III, Mila, 1961; del mismo autor, I diritti sulle cose nella storia del diritto italiano (reimpresión de los cursos de 1906), Giuffré, Mila, 1964; Dusi, B., L'eredità giacente nel dirtto romano e moderno, Turin, 1891; Blandini, C., Del subjetto dell'eredità giacente, en "Antologia giuridica", VI, Catane, 1892; Orestano, R., Diritti soggettivi e senza soggetto. Linee di una vicenda concettuale, Turin, 1959; Leicht, S., Storia del diritto italiano. Il diritto privato. Diritto reali e di successione, Milan, 1960. Acerca de las operaciones elaboradas por el derecho romano para rodear los problemas suscitados por el estado de yacencia, ver Thomas, Y., “Du sien au soi. Questions romaines dans la langue du droit", L'Écrit du temps, 1415, 1987, p. 157-172. Ver además del mismo autor "L'extrême et l'ordinaire. Remarques sur le cas médiéval de la communauté disparue", in Passeron, J.-C. \& Revel, J. (éd.), Penser par cas, Ed. EHESS, Paris, 2005, p. 45-73. El parentezco es estrecho entre este derecho y el derecho de naufragio, al cual hacen referencia, por lo demás, los mismos juristas que intervienen en los procedimientos analizados.

31 Estas expectativas de protección son a veces explícitas: a mediados del siglo XVIII muchos particulares dirigieron al rey una petición solicitando medidas para proteger las propiedades que estaban siendo vendidas o bien transmitidas. Se sugiere que los emblemas reales podrían proteger eventuales tomas de posesión, o bien de usurpaciones que pudieran hacer terceros. Explican que las mismas medidas conciernen a los robos, y más generalmente, el problema del control de las entregas (pasos y traspasos) de propiedad. En enero de 1750, un edicto que busca limitar el fenómeno, prescribe que todos los joyeros, los orfebres, los caldereros, los hojalateros, los ropavejeros, etc., deben informar al Vicario de Justicia toda venta que hayan realizado en sus ventas (ver el Editto di provvedimenti a riguardo dei furti, del 5 de enero de 1750, en Duboin, Editti, t. 6, vol. 8, p. 116 y sgtes.) Durante algunos meses esta medida se siguió, y disponemos por lo tanto de una fuente muy rica (aunque limitada): AST, Sez. Riunite, Vicariato, sentenze criminali, vol. 151. Aún en 1791 se prescribe que toda venta registrada ante notario deberá también volverse pública a través de los "grida davanti al palazzo del Senato", declaraciones de los traspasos de propiedad, dando un plazo de tres meses para quien quiera reivindicar eventuales derechos sobre ellas:

AST, Sez. Riunite, Grida Senatorie, vol. 415, 1791 (debo a Nicoletta Rolla estas enriquecedoras informaciones).
} 
Por ejemplo, en el caso de "Giovanni Perro, quien mientras vivió fue ayuda de cámara del caballero Madris de Lorraine 32 ", muerto en abril de 1753, la persona que recibe al Secretario de la Cámara de Cuentas encargado del procedimiento, es un cierto Pietro Denisio, que se muestra sabedor del estado de riqueza que perteneció a Perron, y especialmente posee todas las escrituras concernientes a sus deudas y créditos, y también un cofre, el cual, según dice, el difunto le habría confiado. Los bienes cuyo depositario se autonombra Denisio son de una extraordinaria riqueza. En efecto, en el transcurso del procedimiento se revela el conjunto de las actividades de Perron. Estas están lejos de resumirse al servicio de cámara; el difunto era un cortesano que "prestaba bienes contra una suma de garantía”, y efectuaba préstamos a partir de muebles que los particulares le confiaban ${ }^{33}$. En las páginas del proceso se dibuja un frenético circuito de objetos que entran y salen de las casas: las sábanas de las camas, que se desarman y se venden para, en seguida ser compradas nuevamente y recompuestas; vestidos y muebles implicados en un movimiento constante, y cada uno de ellos queda inscrito en un mercado de cosas nuevas, de segunda mano, de lo provisorio (es decir, cada cosa ha sido objeto de una evaluación, pero no fue intercambiada) ${ }^{34}$.

Pero regresemos a nuestro problema, que compartimos, de hecho, con El Patrimonial de Su Majestad: ¿por qué y cómo es Pietro Denisio es el guardián y administrador de todas esas riquezas? Declara tener 53 años de edad y, natural de Lyon, reside en Turín desde hace 50 años. Es Topógrafo de Su Majestad. Del difunto, dice: "Conocí al difunto Señor Perron de Lorraine, ayuda de cámara del Señor Conde de Madrus, hace alrededor de cinco o seis años; mientras vivía, vendía y compraba vestidos, muebles y otras mercaderías". El propio Denisio había "hecho mucho comercio" con el difunto, y es su acreedor de la suma no menor de 500 liras. Se trataba de relaciones de negocios regulares, de la cual dan testimonio un buen número de actos de compra y de venta que produjeron a lo largo de esos años ${ }^{35}$. Pero la gran familiaridad entre los esposos Denisio y Perron había nacido sólo el martes de la semana anterior, cuando este último, habiendo enfermado - según Denisio - le mandó llamar para pedirle que no lo abandonase. "En seguida de esta petición hice venir a mi esposa Rosa y nos turnamos en la cabecera de su cama hasta que pasó de esta vida a la otra". Es interrogado sobre los puntos siguientes: "si, durante su última enfermedad, el dicho difunto había sido asistido por otras personas que él mismo y su esposa, y, si es el caso, que declare sus identidades; también, que declare si esas personas eventualmente

\footnotetext{
32 AST, Camerale Piemonte, art. 492, Ubena, m. P. 3, 1753-1775.

${ }^{33}$ En sus testimonios, los judíos Guastalla, Aron Nizza, Verona, describen con gran claridad esta actividad: Ibid.., primo incartamento, cc. 22 y sgtes.

34 Sobre esta pluralidad de los circuitos de intercambio, ver Ago, R., Economia barocca, Op. Cit. Sobre la circulación del crédito en Francia y en Inglaterra, ver Hoffman, P. T., Postel-Vinay, G. \& Rosenthal, J. L., Des marchés sans prix. Une économie politique du crédit à Paris, 1660-1870, Paris, 2001; también Muldrew, C., The Economy of Obligation, New York, 1988; y Finn, M. C., The Character of Credit: Personal Debt in English Culture, 1740-1914, Cambridge U. P., New York, 2003.

35 AST, Sez. Riunite, Insinuazione Torino, 1735, 1. 3, vol. 1, c. 132, en el que se menciona un buen número de transacciones.
} 
presentes hubieran desplazado o incluso sustraído los bienes del Señor Perron". Preguntas y respuestas ponen de manifiesto la preocupación por la integridad del patrimonio; entonces es esencial reconstituir el mapa de los movimientos alrededor de la cama del muriente. En efecto, dos sirvientes habían estado presentes. Todo el mundo recibió "regalos" de parte de Perron; especialmente Denisio, quien, según su propia versión de los hechos, había sido el destinatario de una gran cantidad de objetos, en garantía de sus créditos ("todos los bienes empeñados pertenecientes al Señor Guastalla, judío", esto es cubiertos de plata, boletas de crédito, cobertores de cama de seda, muchos vestidos e incluso un "cofre todavía cerrado"). La visita de los funcionarios en su propia habitación conforta esa versión de los hechos. Sin embargo, nadie cuestiona la legitimidad de esos "dones". En los numerosos testimonios que componen los dos legajos del proceso (más de 400 fojas), emerge con claridad que Denisio, a la cabecera de Perron y también en durante las horas que siguieron a su muerte, actuó como su ejecutor testamentario dando su autorización, o poniendo su veto, a todo movimiento de bienes. Actúa de tal manera que los amigos comunes sugieren al cirujano Laj que le entregue "la espada con puño de plata de París, y el bastón con pomo de plata de la India" que Perron le había dado "como señal de amistad", para disipar "cualquier posible malentendido". Filtra las visitas al enfermo; cuando el mercader judío Aron Nizza fue hasta la cabecera del moribundo para pedirle la restitución de diez preciosos abrigos que había empeñado a cambio de dinero para pagar sus deudas, se encuentra con "un cierto Denisio y su esposa, y como yo quería acercarme de la cama [...] el dicho Denisio me invitóa abandonar la habitación en compañía del valer del Señor Conde de Arcor [...] diciéndome estas palabras formales: 'No te preocupes, vamos a encontrar los abrigos'; y, no estando yo satisfecho con esa respuesta, le respondí que todo eso me parecía demasiado vago". Sin embargo, una vez Perron fallecido, Nizza no pudo siquiera ver el cadáver, porque la esposa de Denisio se autonombró su guardiana. A pesar de la rapidez de la intervención del Fisco, este último llega así a controlar la mayor parte de los bienes del difunto, y sobre todo, los cientos de boletas de crédito que constituían lo esencial de su riqueza.

Durante el corto momento liminar que transcurrió entre la muerte de Perron y la intervención del Fisco, la presencia de Denisio se impuso: y, de hecho, logró imponer su rol central en la sucesión. Trató de darle una legitimidad más segura haciendo aparecer un acto que probaba una donación, dudosa, acto que Perron habría hecho redactar por un notario la víspera de su muerte (se trata de un acto "todavía no registrado", por el cual el notario "aún no ha recibido sus honorarios"). Pero lo esencial no está ahí. El lugar de Denisio en la sucesión de Perron se impuso porque tuvo ventaja en una competencia en la que fue el más ingenioso de los participantes. Bastante más astuto, y más feliz, por ejemplo, que Michel Angelo Brunet de Frossasco, valet de cámara del Marqués Balbis, en Turin, quien, durante los doce últimos años había comprado numerosos bienes que habían sido empeñados (puestos en custodia a cambio de sumas de dinero) y que no habían sido jamás recuperados por sus dueños, y que habían quedado en manos de Perron. Durante la enfermedad de Perron, Brunet 
estaba entre quiénes fueron cotidianamente, en realidad "muchas veces al día", precisó, a su cabecera. Sin embargo, engañado por Denisio, Brunet no asistió a la muerte de Perron. Apenas se entera de ella, se apersona en su casa:

"Para saber quién se había apropiado de su herencia y, en esa ocasión pude observar a un tal llamado Denisio, acompañado por su esposa, que actuaba como dueño de casa, guardando las llaves y utilizándolas para abrir y cerrar armarios, escritorios, cofres, todo a su gusto" $" 36$.

Los malabares se despliegan también para el Conde de Piossasco, aunque, cuando supo de la enfermedad de Perron, encargó a un sirviente suyo el ir a casa de este último para:

"Informarse todos los días del estado de salud del dicho Perron [...] y cada vez que yo mismo iba, siempre fui recibido por el dicho Denisio salvo una vez por su esposa; uno y otro me tranquilizaban diciendo que Perron iba cada vez mejor".

El objetivo de la astucia se logró. El Conde no está en casa de Perron al momento de su muerte; y a pesar de que se precipita a la casa, alcanzando a entrever el cadáver, encuentra allí a Denisio que actúa, a partir de entonces, como dueño, y por el contrario, no encuentra ninguna huella de las preciosas cajas de tabaco que había empeñado al difunto ${ }^{37}$.

En esta competencia el Fisco no supo jugar la única carta que habría legitimado su superioridad: el poner los emblemas y los sellos que habrían protegido la propiedad de la toma de posesión de los particulares. Deberá transigir con Denisio, porque este último no puede ser tratado de ladrón. La usurpación de los derechos del Fisco, empero muy real, se llevó a cabo en un escenario que en resumen fue legítimo. En el momento en el que los bienes de Perron se encontraban en un estado liminar, Denisio "actuó como dueño", sin levantar fuertes "contradicciones".

Esta fragilidad de la propiedad implica una vulnerabilidad de las líneas de sucesión; y, en consecuencia, de las parentelas entre ellas, ya que el hecho de heredar "crea" lazos que podrían ser reivindicados del mismo modo que los lazos de sangre: lo veremos más adelante. Por el momento, sólo subrayamos que el sentido de ciertas sanciones golpea a los extranjeros, sanciones que están presentes en los estatus de los siglos XIV y XV, y que ese sentido se hace más claro en el marco del estatus de la propiedad. No se trata de formas de xenofobia o de desconfianza que estarían ligadas al origen geográfico de las personas, sino más bien a la manifestación de preocupaciones familiares (a menudo masculinas) por el control de la descendencia. El estatus de la ciudad de Turin en 1360, por ejemplo, no menciona extranjeros sino en el marco de las prescripciones relativas a los funerales ${ }^{38}$. Estaba formalmente prohibido, a cualquier miembro de la familia del

\footnotetext{
36 AST, Camerale Piemonte, art. 492, Ubena, m., P. 3, 1753-1775, ya citado; primo incartamento, cc. 28-35.

${ }^{37}$ Ibid., c. 39v.

38 Bizzardi, D., Gli statuti del Comune di Torino nel 1360, Turin, 1933, cap. 321, p. 1333.
} 
difunto, invitar a personas extranjeras cuando el cadáver estaba aún dentro de su propia casa. No se podía negar techo y pan a los "extranjeros" que llegaran de improviso, pero su presencia no podía deberse, bajo ninguna circunstancia, a una invitación. Por lo tanto, no era la presencia en sí misma de una persona extranjera lo que era percibido como amenazante, sino más bien la acogida en el seno de la domus, que habría podido suscitar una familiaridad con sus riquezas y, a continuación, reivindicaciones de los derechos a ellas. Esta misma preocupación dicta, algunas líneas más arriba, prescripciones que conciernen a las mujeres ligadas al difunto hasta el cuarto grado de parentela: mientras el cadáver no haya recibido sepultura, ellas no tienen derecho de salir de la casa. La protección de las líneas de descendencia es dominante: el momento de la muerte es potencialmente muy peligroso.

\section{Líneas de sucesión y derechos de pertenencia local}

La capacidad de atribuir derechos, y por lo tanto de crear estatus sociales, no concierne solamente el ámbito de la propiedad. También concierne al ámbito de la parentela, y según muchos aspectos. Para empezar, y ello debe ser mirado de cerca, la condición de heredero está vinculada, más que a un estatus, a una acción. La fuente muestra con claridad que - parafraseando una valiosa reflexión de Marguerite Vanel ${ }^{39}$ - un individuo no hereda porque es heredero legítimo; es más bien el hecho de haber heredado lo que hace de él un heredero legítimo. En consecuencia, a partir del momento en que el problema de las líneas de sucesión se sitúa en el corazón de los procedimientos suscitados por el derecho de advenia, estos procedimientos son también el lugar de construcción de la parentela (y no solamente de su reconocimiento).

Un ejemplo entre otros. En 1724, a la muerte del Señor Federico Vidmar, "de nación alemana", grabador en el Hotel de la Moneda, el Fisco intervino, como de costumbre, para proteger, y eventualmente confiscar, sus propiedades. Extranjero, sin hijos, Vidmar fallece sin haber puesto por escrito su última voluntad. Sin embargo, aparece un pretendiente a su herencia, lleno de argumentos que él considera como más que sólidos. El Comendador Giovanni Battista Emser, coronel de la Artillería de Su Majestad, trae como prueba del bien fundado de sus pretensiones un hecho simple que, no obstante, parece decisivo: ha sido encargado por el difunto de la distribución de sus legados y de sus donaciones. Esta acción, que cumple con esmero, legitima sus

\footnotetext{
${ }^{39}$ En las sociedades de Antiguo Régimen, "las reglas jurídicas evolucionaron primero debido a un motivo de orden sucesorio, en consecuencia, en un interés puramente privado. La teoría de una ciudadanía debía precisarse únicamente porque la liquidación de una sucesión cuestionaba su valor [...] Dicho de otra manera, un individuo no es sucesor porque es francés, es francés porque es lógico que sea sucesor": Vanel, M., Évolution historique de la notion de Français d'origine du XVTè siècle au code civil. Contribution à l'étude de la nationalité française d'origine, Ancienne imprimerie de la Cour d'Appel, Paris, 1945, p. 54-55.
} 
pretensiones de suspender el derecho de advenia. Asumiendo las prerrogativas de un descendiente, el Comendador ha adquirido de hecho el estatus de tal ${ }^{40}$.

Son muy frecuentes las huellas de esos comportamientos, es decir, de estas estrategias de construcción de líneas de descendencia que no se apoyan en la sangre, ni siquiera en relaciones de alianza. La difusión de la institución de beneficios entre aquéllos que están desprovistos de herederos "naturales" es prueba de ello. Los legados hechos a una institución eclesiástica se acompañan de la designación de un individuo que estará encargado de nombrar al clero que celebrará las misas en memoria del difunto y de administrar la propiedad que es fuente de recursos de esos legados. En los hechos, esta designación esconde la voluntad del testador de dibujar un eje de descendencia particular, escogido por él mismo, antes que inscrito en los vínculos de parentela. Con Federico Vidmar, muchos otros "extranjeros" actúan del mismo modo en el territorio piemontés ${ }^{41}$. Es debido a esta razón (es decir, a causa de este uso) que tanto en El Piemonte como en Francia, todo edicto que instituye el derecho de advenia prohíbe a los extranjeros instituir beneficios ${ }^{42}$. El Fisco Real teme, con justa razón, este uso instrumental de los beneficios en tanto fábricas de "líneas de descendencia"; porque nada es más evidente que la relación circular existente entre esta construcción, la parentela, y finalmente la naturalización. Marguerite Vanel tiene profunda razón: "un individuo no es sucesor porque es francés, es francés porque es lógico que él sea sucesor". No solamente la corona no poseyó jamás el monopolio de la atribución de la ciudadanía y de la naturalización, pero además se encuentra compitiendo constantemente con los individuos que manifiestan una gran capacidad de manipular esta lógica centrada en la acción. Por otro lado, esta lógica se sitúa en el origen del principio del mismo derecho de advenia; es la capacidad del Fisco de poder ser sucesor de los extranjeros lo que legitima las pretensiones de la corona de ser, bajo todos los aspectos, la familia electiva.

Hablando de propiedad y de transmisión, el derecho de advenia habla por lo tanto también de extranjeros, de individuos que se definen y son reconocidos como extranjeros, no por su relación a un territorio, sino respecto a una línea de descendencia. Por lo demás, en el mismo momento en que Jean Bocquet y Jean Bodin transformaban el derecho de advenia en derecho real sobre las poblaciones extranjeras de un territorio, otros juristas franceses reflexionaban sobre el mismo problema bajo otro punto de vista, muy cercano a aquello que surge de las fuentes que hemos

\footnotetext{
40 AST, Camerale Piemonte, art. 492, Ubena, m. V-Z/3, Federico Vidmar, 1724-1725.

${ }^{41}$ Ver en particular Ibid., m. D/F2, Biagio di Giorgi, 1734, del cual encontré el testamento en AST, Sez. Riunite, Insinuazione Torino, 1734, vol. 11, c. 151v, 5 de noviembre de 1734.

42 Esta prohibición se acompaña de aquélla que concierne la prohibición de cargos públicos, porque detentarlos puede desencadenar también reivindicaciones de pertenencia. En el caso de los bienes del Capitán Carlo Antonio Bombelli, sus hijos pretenden tener derecho a su herencia porque, según dicen, su padre se había transformado en un "originario" del lugar, y la prueba era exactamente el hecho que detentaba oficios "quali non si davano a quelli residenti da meno de venti anni [...] e si solevano dare a persone originarie": AST, Camerale Piemonti, art. 492, Ubena, m. A. B/2, Capitano Bombelli di Ceva, 1621.
} 
analizado hasta aquí. La condición del extranjero como alguien desprovisto de familia, o para decirlo mejor, de una sucesión (más que el hecho de pertenecer a otro lugar), estaba en el corazón de la reflexión de esos juristas que se mostraban atentos a la costumbre y a los diferentes derechos locales. El jurista De Cormis, autor de una recopilación de jurisprudencia de la región de Provence del siglo XVII, era muy explícito a este respecto. Escribiendo sobre un texto del siglo XV, que trataba sobre "el pago del laudemio sobre la institución del heredero ab intestato", no vacilaba en afirmar que, en esos casos, "las personas extranjeras" son claramente "los parientes colaterales, como hermanos, tíos, sobrinos, primos hermanos, y los maridos y las esposas". "Solamente los ascendientes y los descendientes en línea directa no son, en el caso que interesa, extranjeros" 43 .

Hermanos, tíos, sobrinos, primos hermanos, maridos, esposas: son extranjeros en la medida en que serán excluidos de una sucesión directa. Es ésta la línea que otorga la medida a la extranjeridad, y no la pertenencia a un territorio. Esta concepción, desestabilizadora para nosotros, sólo puede comprenderse al interior de esta cultura de la propiedad, de la que hemos tratado aquí de exponer algunos contornos.

"Es necesario recordar [escribía sobre este tema Enrico Besta, comentando el sistema sucesorio de las sociedades de Antiguo Régimen], que los bienes que, habiendo pertenecido a alguien, le hayan sobrevivido, se transformaban en bienes que pertenecían al grupo. El extranjero no puede ser un sucesor. El extranjero respecto del grupo podía ser también eso que nosotros llamamos un pariente. Si una mujer deja su grupo de origen para pasar a otro, ella se transforma en extranjera para el primero, mientras que el marido que sigue a su esposa entra en el grupo de ella [...] En ese caso, la primera pierde los derechos a la sucesión; en el segundo caso, en cambio, esos derechos se actualizan ${ }^{44,}$.

Es a causa de esta centralidad de las líneas de sucesión en la capacidad de designar a los "extranjeros" (como a los no-extranjeros) que, en los procedimientos concernientes al derecho de advenia, las disposiciones del difunto (testamentos, donaciones, beneficios) son pruebas mucho más eficaces para probar el derecho a la herencia que las cartas de naturalización. Y es por esta razón que estas últimas fueron solicitadas por un número bien restringido de personas: "para una mayor prudencia" como confiesan algunos - y la fórmula remite sin ninguna duda a situaciones de conflicto y cuestionamientos.

\footnotetext{
43 Citado en Dolan, C., "Famille et intégration des étrangers à Aix-en-Provence au XVIè siècle", Provence Historique, 35, 1985, p. 401-413 (p. 402).

44 "Bisogna ricordare che $i$ beni che, dopo aber appartenuto al singolo, non erano distrutti erano appunto beni che appartenevano al gruppo. L'estraneo non può succedere. Estraneo avendo riguardo alla composizione del gruppo poté pur essere quello che noi chiamiamo un parente. Se una donna esce dal gruppo originario per passare ad un altro, ad esso si estranea ed entra invece in esso il marito che venga a collocarsi presso la moglie [...] Per quella i diritti successori cessano, per questo si affermano." (Besta, Le successioni, Op. Cit., p. 47).
} 
La nacionalidad en la época moderna sólo se comprende en su vínculo con la descendencia, en la cual el parentesco es sólo un aspecto más. Ese es el lugar que constituye el "anclaje social" al que hacen referencia ciertas investigaciones citadas en la introducción. El vínculo entre las dos es tan estrecho que cualquier historia de nacionalidad que se detenga sólo en la esfera política y no tomara en cuenta el campo de los vínculos patrimoniales y sucesorios, corre el riesgo de caer en el anacronismo.

\footnotetext{
Traducido por María Eugenia ALBORNOZ VASQUEZ, Doctora (C) en Historia (EHESS de Paris) y
} Aude ARGOUSE, Doctora en Historia (EHESS de Paris) 